\title{
Domestic Exposure to Polycyclic Aromatic Hydrocarbons in a Houston, Texas, Environmental Justice Neighborhood
}

\author{
Garett T. Sansom, Katie R. Kirsch, Kahler W. Stone, Thomas J. McDonald, \\ and Jennifer A. Horney
}

\begin{abstract}
Polycyclic aromatic hydrocarbons (PAHs) are a class of $>100$ chemicals that naturally occur in coal tar, crude oil, and gasoline and can be manufactured as part of dyes, plastics, and pesticides. PAHs are complex environmental toxicants and exposure to them have been linked to adverse health outcomes including cancer, as well as diseases of the skin, liver, and immune system. Residents of the environmental justice neighborhood of Manchester, located on Houston's East End, are disproportionally exposed to toxic pollutants from both industry and transportation infrastructure. Based on a longstanding community engagement partnership with the research team, neighborhood residents sought to better understand their domestic exposure to PAHs. Particulate wipes were used to collect dust from a marked area within the entryway of randomly selected homes to assess for the presence of PAHs. Nineteen of the 61 PAH analytes, including the Environmental Protection Administration's 16 priority PAHs and the subgroup of 7 probable human carcinogens, were found in the sampled homes. Residents of the Houston neighborhood of Manchester potentially have significant domestic exposure to PAHs from combustion sources. More research is needed to assess the source of the PAHs and to better understand the potential health impacts of these exposures.
\end{abstract}

Keywords: PAH, environmental justice, domestic exposure, environmental contaminants

\section{INTRODUCTION}

$\mathbf{C}$ OMPLEX ENVIRONMENTAL TOXICANTS such as polycyclic aromatic hydrocarbons (PAHs) can have negative impacts on human health. Although prior research has quantified levels of exposure and subsequent potential health implications of PAHs in many occupational settings, ${ }^{1}$ more information is needed to quantify

Dr. Garett T. Sansom is associate director at Institute for Sustainable Communities, Texas A\&M University, College Station, Texas. Katie R. Kirsch is a research associate at Department of Epidemiology and Biostatistics, Texas A\&M School of Public Health, College Station, Texas. Kahler W. Stone is a graduate research assistant at Department of Epidemiology and Biostatistics, Texas A\&M School of Public Health, College Station, Texas. Dr. Thomas J. McDonald is a professor at Department of Environmental and Occupational Health, Texas A\&M School of Public Health, College Station, Texas. Dr. Jennifer A. Horney is an associate professor at Department of Epidemiology and Biostatistics, Texas A\&M School of Public Health, College Station, Texas.
${ }^{1}$ Cristina Bosetti, Paolo Boffetta, and Carlo La Vecchia. "Occupational Exposures to Polycyclic Aromatic Hydrocarbons, and Respiratory and Urinary Tract Cancers: A Quantitative Review to 2005." Annals of Oncology 18 (2007): 431-446; Peter H. Langlois, Adrienne T. Hoyt, Philip J. Lupo, Christina C. Lawson, Martha A. Waters, Tania A. Desrosiers, Gary M. Shaw, Paul A. Romitti, and Edward J. Lammer. "Maternal Occupational Exposure to Polycyclic Aromatic Hydrocarbons and Risk of Oral Cleft-Affected Pregnancies." The Cleft Palate-Craniofacial Journal 50 (2013): 337-346; Philip J. Lupo, Peter H. Langlois, Jennita Reefhuis, Christina C. Lawson, Elaine Symanski, Tania A. Desrosiers, Zenia Khodr, et al.; National Birth Defects Prevention Study "Maternal Occupational Exposure to Polycyclic Aromatic Hydrocarbons: Effects on Gastroschisis Among Offspring in the National Birth Defects Prevention Study." Environmental Health Perspectives 120 (2012): 910-915; Jacqueline L. O'Brien, Peter H. Langlois, Christina C. Lawson, Angela Scheuerle, Carissa M. Rocheleau, Martha A. Waters, Elaine Symanski, Paul A. Romitti, A.J. Agopian, and Philip J. Lupo; National Birth Defects Prevention Study. "Maternal Occupational Exposure to Polycyclic Aromatic Hydrocarbons and Craniosynostosis Among Offspring in the National Birth Defects Prevention Study." Birth Defects Research Part A, Clinical and Molecular Teratology 106 (2016): 55-60. 
domestic exposures and their potential health impacts. ${ }^{2}$ Settled dust and particulate matter within homes can be an important exposure route for individuals, in general, and children, in particular. As part of a community-engaged research study coordinated by the Institute for Sustainable Communities (IfSC) at Texas A\&M University, we worked with Texas Environmental Justice Advocacy Services (TEJAS), an environmental justice advocacy group representing the residents of Manchester, an environmental justice community in Houston, Texas, to collect settled dust in homes and assess it for the presence of PAHs. The assessment of PAHs is part of the community's effort, supported by the IfSC, to obtain a more complete picture of resident's ongoing environmental exposures and their potential contribution to health risks.

PAHs are an important group of $>100$ organic compounds that are composed of carbon and hydrogen atoms and contain two or more benzene rings. The majority of PAH production is attributed to incomplete combustion of carbon-containing materials such as petroleum consumption in transportation or natural processes such as wildfires. ${ }^{3}$ The U.S. Environmental Protection Administration (EPA) classified 16 PAHs as priority pollutants in $1976 .{ }^{4}$ The selection criteria included known toxicity to humans, occurrence in the environment, and the analytical capabilities that were available in the 1970 s. $^{5}$ Seven of these priority pollutants-

${ }^{2}$ Curt T. DellaVale, Nicole C. Deziel, Rena R. Jones, Joanne S. Colt, Anneclaire J. De Roos, James R. Cerhan, Wendy Cozen, et al. "Polycyclic Aromatic Hydrocarbons: Determinants of Residential Carpet Dust Levels and Risk of Non-Hodgkin Lymphoma." Cancer Causes \& Control 27 (2016): 1-13; Nicole Cardello Deziel, Rudolph P. Rull, Joanne S. Colt, Peggy J. Reynolds, Todd P. Whitehead, Robert B. Gunier, Stacy R Month, et al. "Polycyclic Aromatic Hydrocarbons in Residential Dust and Risk of Childhood Acute Lymphoblastic Leukemia" Environmental Research 133 (2014): 388-395; Yuan Kang, Dingding Shao, Ning Li, Gelin Yang, Qiuyun Zhang, Lixuan Zeng, Jiwen Luo, and Wenfeng Zhong. "Cancer Risk Assessment of Human Exposure to Polycyclic Aromatic Hydrocarbons (PAHs) via Indoor and Outdoor Dust Based on Probit Model.' Environmental Science and Pollution Research 22 (2015): 3451-3456; Chungyih Kuo, Y.W. Hsu, and Hongshen Lee, "Study of Human Exposure to Particular PAHs Using Personal Air Samplers." Archives of Environmental Contamination and Toxicology 44 (2003): 454-459; Ki-Hyun Kim, Shamin Ara Jahan, Ehsanul Kabir, and Richard J.C. Brown. "A Review of Airborne Polycyclic Aromatic Hydrocarbons (PAHs) and Their Human Health Effects.' Environment International 60 (2013): $71-80$.

${ }^{3}$ ATSDR. ATSDR's Toxicological Profiles on CD-ROM. In: Toxicology Profile for Polyaromatic Hydrocarbons. (CRC Press, Boca Raton, 2005); Yanxu Zhang, Shu Tao. "Global Atmospheric Emission Inventory of Polycyclic Aromatic Hydrocarbons for 2004." Atmospheric Environment 43 (2009): 812 819; Huizhong Shen, Ye Huang, Rong Wang, Dan Zhu, Wei Li, Guofeng Shen, Bin Wang, et al. "Global Atmospheric Emissions of Polycyclic Aromatic Hydrocarbons from 1960 to 2008 and Future Predictions." Environmental Science \& Technology 47 (2013): 6415-6424.

${ }^{4}$ ATSDR, 2005.

${ }^{5}$ Lawrence H. Keith. "The Source of U.S. EPA's Sixteen PAH Priority Pollutants." Polycyclic Aromatic Compounds 35 (2015): 147-160. designated by the EPA as Group B2-are classified as probable human carcinogens, including (benzo(a)anthracene, chrysene, benzo(a)pyrene, benzo(b)fluoranthene, benzo(k)fluoranthene, dibenz(a,h)anthracene, and indeno (1,2,3-cd)pyrene). ${ }^{6}$ More recent research suggests that more PAHs should be included in human health assessment studies. ${ }^{7}$

The human health impacts of PAHs are dependent upon the toxicity and concentration of the compounds to which an individual is exposed, as well as the period of exposure (chronic vs. acute), route of exposure, and individual immunological capacity. ${ }^{8}$ The most common routes of exposure are inhalation and dermal absorption. ${ }^{9}$ Infants and children are especially prone to dermal contact with contaminants in settled household dust, as they typically spend relatively greater periods of time in contact with floors and other surfaces where dust accumulates. ${ }^{10}$ The propensity of children to engage in frequent hand-to-mouth activity may also increase the risk of ingestion of dust-bound contaminants. ${ }^{11}$ Other means of PAH ingestion include consumption of drinking water and food that has become contaminated from environmental sources or exposure to high-temperature processing or cooking of certain foods. ${ }^{12}$

Prenatal exposure to excess levels of airborne PAHs has been associated with deficits in developmental milestones, including reduced nonverbal reasoning ability, mean IQ points, ${ }^{13}$ social competence,

${ }^{6}$ National Toxicology Program (NTP). Report on Carcinogens, eleventh ed. (Public Health Service, US Department of Health and Human Services, Washington, 2005).

${ }^{7} J a n$ T. Andersson and Christine Achten. "Time to Say Goodbye to the 16 EPA PAHs? Toward an Up-to-Date Use of PACs for Environmental Purposes." Polycyclic Aromatic Compounds 35 (2015): 330-354.

${ }^{8}$ ATSDR, 2005.

${ }^{9}$ Szu-Chich Chen and Chung-Min Liao. "Health Risk Assessment on Human Exposed to Environmental Polycyclic Aromatic Hydrocarbons Pollution Sources." Science of the Total Environment 366 (2006): 112-123.

${ }^{10}$ Environmental Protection Agency (EPA). America's Children and the Environment, third ed. (US EPA, Washington, 2013).

${ }^{11}$ Nicolle S. Tulve, Jack C. Suggs, Thomas McCurdy, Elaine A. Cohen Hubal, and Jacqueline Moya. "Frequency of Mouthing Behavior in Young Children." Journal of Exposure Analysis and Environmental Epidemiology 12 (2002): 259-264; Ross Wilson, Heather Jones-Otazo, Sanya Petrovic, Ian Mitchell, Yvette Bonvalot, David Williams, and G. Mark Richardson. "Revisiting Dust and Soil Ingestion Rates Based on Hand-to-Mouth Transfer." Human and Ecological Risk Assessment 19 (2013): 158-188.

${ }^{12}$ Neely Kazerouni, Rashmi Sinha, Che-Han Hsu, A. Greenberg, and N. Rothman. "Analysis of 200 Food Items for Benzo[a]pyrene and Estimation of Its Intake in an Epidemiologic Study." Food and Chemical Toxicology 39 (2001): 423-236; Zuzana Zelinkova and Thomas Wenzl. "The Occurrence of 16 EPA PAHs in Food-A Review." Polycyclic Aromatic Compounds 35 (2015): 248-284.

${ }^{13}$ Susan Claire Edwards, Wieslaw Jedrychowski, Maria Butscher, David Camann, Agnieszka Kieltyka, Elzbieta Mroz, Elzbieta Flak, et al.. "Prenatal Exposure to Airborne Polycyclic Aromatic Hydrocarbons and Children's Intelligence at 5 Years of Age in a Prospective Cohort Study in Poland." Environmental Health Perspectives 118 (2010): 1326-1331. 
and self-regulation, ${ }^{14}$ as well as higher measures of anxiety, depression, and attention problems. ${ }^{15}$ Intrauterine exposure to high concentrations of PAHs has also been linked to physical impairments, impaired fetal growth, ${ }^{16}$ and congenital malformations such as gastroschisis ${ }^{17}$ craniosynostosis ${ }^{18}$ oral clefts,${ }^{19}$ and neural tube defects. ${ }^{20}$ Lasting health effects have been reported in children after fetal PAH exposure, including decreased height growth ${ }^{21}$ and childhood obesity. ${ }^{22}$ PAH exposure has also been linked to respiratory distress in asthmatic children. ${ }^{23}$ Chronic exposure in adults has been linked to the development of breast, lung, gastro-

\footnotetext{
${ }^{14}$ Amy E. Margolis, Julie B. Herbstman, Katie S. Davis, Valerie K. Thomas, Deliang Tang, Ya Wang, Shuang Wang, Frederica P. Perera, Bradley S. Peterson, and Virginia A. Rauh. "Longitudinal Effects of Prenatal Exposure to Air Pollutants on Self-Regulatory Capacities and Social Competence." Journal of Child Psychology and Psychiatry 57 (2016): 851-860.

${ }^{15}$ Frederica P. Perera, Deliang Tang, Shuang Wang, Julia Vishnevetsky, Bingzhi Zhang, Diurka Diaz, David Camann, and Virginia Rauh. "Prenatal Polycyclic Aromatic Hydrocarbon (PAH) Exposure and Child Behavior at Age 6-7 Years." Environmental Health Perspectives 120 (2012): 921-926.

${ }^{16}$ Hyunok Choi, Lu Wang, Xihong Lin, John D. Spengler, and Frederica P. Perera. "Fetal Window of Vulnerability to Airborne Polycyclic Aromatic Hydrocarbons on Proportional Intrauterine Growth Restriction." PLoS One 7 (2012): e35464; Wieslaw A. Jedrychowski, Renata Majewska, Jack D. Spengler, David Camann, Emily L. Roen, and Frederica P. Perera. "Prenatal Exposure to Fine Particles and Polycyclic Aromatic Hydrocarbons and Birth Outcomes: A Two-Pollutant Approach." International Archives of Occupational and Environmental Health 90 (2017): 255-264.

${ }^{17}$ Lupo et al., 2012.

${ }^{18}$ O'Brien et al., 2016

${ }^{19}$ Langlois et al., 2013.
}

${ }^{20}$ Aiguo Ren, Xinghua Qiu, Lei Jin, Jin Ma, Zhiwen Li, Le Zhang, Huiping Zhu, Richard H. Finnell, and Tong Zhu. "Association of Selected Persistent Organic Pollutants in the Placenta with the Risk of Neural Tube Defects." Proceedings of the National Academy of Sciences of the United States of America 108 (2011): 12770-12775.

${ }^{21}$ Wieslaw A. Jedrychowski, Frederica P. Perera, Renata Majewska, Dorota Mrozek-Budzyn, Elzbieta Mroz, Emily L. Roen, Agata Sowa, and Ryszard Jacek. "Depressed Height Gain of Children Associated with Intrauterine Exposure to Polycyclic Aromatic Hydrocarbons (PAH) and Heavy Metals: The Cohort Prospective Study." Environmental Research 136 (2015): 141-147.

${ }^{22}$ Andrew Rundle, Lori Hoepner, Abeer Hassoun, Sharon Oberfield, Greg Freyer, Darrell Holmes, Marilyn Reyes, et al. "Association of Childhood Obesity with Maternal Exposure to Ambient Air Polycyclic Aromatic Hydrocarbons During Pregnancy" American Journal of Epidemiology 175 (2012): $1163-1172$

${ }^{23}$ Sara L. Gale, Elizabeth M. Noth, Jennifer Mann, John Balmes, S. Katharine Hammond, and Ira B. Tager. "Polycyclic Aromatic Hydrocarbon Exposure and Wheeze in a Cohort of Children with Asthma in Fresno, CA." Journal of Exposure Science \& Environmental Epidemiology 22 (2012): 386-392. intestinal, and bladder cancers. ${ }^{24}$ Although the majority of studies investigating $\mathrm{PAH}$-associated cancers have focused on occupational exposures, ${ }^{25}$ a growing body of evidence has highlighted the need for additional research in residential settings. ${ }^{26}$

Prior research has demonstrated inequitable exposure to environmental risks from the lived environmental conditions of low socioeconomic status and minority communities within the United States. ${ }^{27} \mathrm{Al}-$ though many research and community engagement efforts have attempted to understand and mitigate these discriminatory environmental exposures, this process has been slow and the types of observational studies that have typically been conducted have at times been viewed as providing inadequate evidence by both researchers and affected communities. ${ }^{28}$ However, there is some research addressing the observed linkages between exposure to PAHs and disease in environmental justice neighborhoods. Using data from the U.S. National Health and Nutrition Examination Survey (NHANES), Tyrrell ${ }^{29}$ demonstrated a significant negative association between poverty-to-income ratio and PAH loads present in biological samples. PAH exposure, in combination with significant recurrent maternal material hardship and high levels of maternal psychological distress, has also been associated with

${ }^{24}$ Ben Armstrong, Emma Hutchinson, John Unwin, and
Tony Fletcher. "Lung Cancer Risk After Exposure to Poly-
cyclic Aromatic Hydrocarbons: A Review and Meta-
analysis." Environmental Health Perspectives 112 (2004):
$970-978 ;$ Bosetti et al., 2007; Giuseppe Mastrangelo, Ema-
nuela Fadda, and Vita Marzia. "Polycyclic Aromatic Hydro-
carbons and Cancer in Man." Environmental Health Per-
spectives., 104 (1996): 1166-1170; Irina Mordukhovich, Jan
Beyea, Amy H. Herring, Maureen Hatch, Steven D. Stellman,
Susan L. Teitelbaum, David B. Richardson, et al. "Vehicular
Traffic-Related Polycyclic Aromatic Hydrocarbon Exposure
and Breast Cancer Incidence: The Long Island Breast Cancer
Study Project (LIBCSP)." Environmental Health Perspectives
124 (2016): 30-38; Jie Zhang, Peng Wang, Jingyi Li, Pauline
Mendola, Seth Sherman, and Qi Ying. "Estimating Population
Exposure to Ambient Polycyclic Aromatic Hydrocarbon in the
United States-Part II: Source Apportionment and Cancer
Risk Assessment." Environment International 97 (2016):
$163-170$.
${ }_{25}$ Bosetti et al., 1996.
${ }^{26}$ DellaVale et al., 2016; Deziel et al., 2014; Kang et al.,
2015. Environmental Quality, third ed. (Westview Press, Boulder, 2000); Douglas L. Anderton, Andy B. Anderson, Peter H. Rossi, John Michael Oakes, Michael R. Fraser, Eleanor W. Weber, and Edward J. Calabrese. "Hazardous Waste Facilities "Environmental Equity" Issues in Metropolitan Areas." Evaluation Review 18 (1994):123-140.

${ }^{28}$ William Bowen. "An Analytical Review of Environmental Justice Research: What Do We Really Know?." Environmental Management 29 (2002): 3-15.

${ }^{29}$ Jessica Tyrrell, David Melzer, William Henley, Tamara S. Galloway, and Nicholas J. Osborne. "Associations Between Socioeconomic Status and Environmental Toxicant Concentrations in Adults in the USA: NHANES 2001-2010." Environment International 59 (2013): 328-335. 
reductions in child IQ and neurodevelopmental problems in children. ${ }^{30}$

\section{METHODS}

\section{Study location}

Manchester, Texas, is a geographically compact primarily Hispanic neighborhood in eastern Houston located on the Houston Ship Channel (Fig. 1). Individuals living within this community experience conditions typical to environmental justice communities including acute and chronic pollution, ${ }^{31}$ nuisance flooding, ${ }^{32}$ air pollution, ${ }^{33}$ and harmful surface water. $^{34}$ Houston Ship Channel communities are at particularly high risk of impacts from the nexus of exposure to hazardous substances and natural disasters. For example, within 1 mile of the Manchester neighborhood, there are 21 facilities that report to the EPA's Toxic Release Inventory: 11 large quantity generators of hazardous waste, 4 facilities that treat, store, or dispose of hazardous wastes, 9 major dischargers of air pollution, and eight major storm water

\footnotetext{
${ }^{30}$ Julia Vishnevetsky, Deliang Tang, Hsin-Wen Chang, Emily L. Roen, Ya Wang, Virginia Rauh, Shuang Wang, Rachel L. Miller, Julie Herbstman, and Frederica P. Perera. "Combined Effects of Prenatal Polycyclic Aromatic Hydrocarbons and Material Hardship on Child IQ." Neurotoxicology and Teratology 49 (2015): 74-80; Frederica P. Perera, Shuang Wang, Virginia Rauh, Hui Zhou, Laura Stigter, David Camann, Wieslaw Jedrychowski, Elzbieta Mroz, and Renata Majewska. "Prenatal Exposure to Air Pollution, Maternal Psychological Distress, and Child Behavior." Pediatrics 132 (2013):e1284e1294.

${ }^{31}$ Jayajit Chakraborty, Timothy W. Collins, Sara E. Grineski, Marilyn C. Montgomery, and Maricarmen Hernandez. "Comparing Disproportionate Exposure to Acute and Chronic Pollution Risks: A Case Study in Houston, Texas." Risk Analysis 34 (2014): 2005-2020.

${ }^{32}$ Houston Chronicle. Harris County wet spots. 2001. <http:// www.chron.com/news/houston-texas/article/Harris-County-wetspots-2051449.php>. (Last accessed on November 4, 2016); Collins, Timothy W., Sara E. Grineski, and Jayajit Chakraborty. "Environmental Injustice and Flood Risk: A Conceptual Model and Case Comparison of Metropolitan Miami and Houston, USA." Regional Environmental Change 18 (2018): 311-323.

${ }^{33}$ Ken Sexton, Stephen H. Linder, Dritana Marko, Heidi Bethel, and Philip J. Lupo2007. "Comparative Assessment of Air Pollution-Related Health Risks in Houston." Environmental Health Perspectives 115 (2007): 1388-1393; Stephen H. Linder, Dritana Marko, and Ken Sexton. "Cumulative Cancer Risk from Air Pollution in Houston: Disparities in Risk Burden and Social Disadvantage." Environmental Science \& Technology 42 (2008): 4312-4322; Timothy W. Collins, Sara E. Grineski, Jayajit Chakraborty, Marilyn C. Montgomery, and Maricarmen Hernandez. "Downscaling Environmental Justice Analysis: Determinants of Household-Level Hazardous Air Pollutant Exposure in Greater Houston." Annals of the Association of American Geographers 105 (2015): 685-703.

${ }^{34}$ Garett T. Sansom, Philip Berke, Thomas J. McDonald, Eva Shipp, and Jennifer A. Horney. "Confirming the Environmental Concerns of Community Members Utilizing Participatory-Based Research in the Houston Neighborhood of Manchester."' International Journal of Environmental Research and Public Health 13 (2016): e839.
}

discharging facilities. ${ }^{35}$ The population of the Manchester Super Neighborhood is $98 \%$ minority, with a median income that is one-third less than that of the City of Houston overall. Only $6 \%$ of residents have obtained a Bachelor's degree. ${ }^{36}$

In addition to environmental concerns, observational studies have documented adverse health outcomes within this community. A report published by the University of Texas Health Science Center found that children living within 2 miles of the Houston Ship Channel had a 56\% increased risk of contracting acute lymphocytic leukemia associated with exposure to emissions of 1,3-butadiene from petrochemical industries. ${ }^{37}$ Other studies have shown significant reductions in general composite health scores in comparison with the City of Houston and the State of Texas. ${ }^{38}$ The Houston Health Department reports that these community members have higher mortality rates for all causes of death and particularly discordant rates for coronary heart disease and cancer in comparison with greater Houston. ${ }^{39}$

\section{Site selection}

Utilizing geographic information systems ArcMap (ESRI, Redlands, CA), 25 homes were randomly selected within the boundary of the Manchester neighborhood. Community partners TEJAS, who were already engaged with ongoing projects with the IfSC at Texas A\&M University, assisted with data collection to help increase response rates. Five teams of four individuals, consisting of trained graduate students from the EpiAssist program at the Texas A\&M University School of Public Health and TEJAS staff approached each home during December of 2016 to obtain consent, complete a survey, and collect samples. Each team had at least one Spanish speaker. This project and all related materials were reviewed and approved by the Texas A\&M University Institutional Review Board (IRB 2016-0698D). If a home was completely fenced off or abandoned, or if the

\footnotetext{
${ }^{35}$ Environmental Protection Agency (EPA). EnviroFacts. 2016. $<$ http://www.epa.gov/enviro $>$. (Last accessed on 16.03.15).

${ }^{36}$ City of Houston Planning and Development Department. Harrisburg/Manchester super neighborhood. 2014. <http:// www.houstontx.gov/superneighborhoods/65.html $>$ (Last accessed on 15.12.07).

${ }^{37}$ Kristina M. Walker, Ann L. Coker, Elaine Symanski, and Philip J. Lupo. A preliminary investigation of the association between hazardous air pollutants and lymphohematopoietic cancer risk among residents of Harris County, Texas. 2006. <http://www.houstontx.gov/health/UT-executive.html> (Last accessed on 16.03.15).

${ }^{38}$ Garett T. Sansom, Juan Parras, Ana Parras, Yudith Nieto, Yvette Arellano, Philip Berke, Thomas J. McDonald, Eva Shipp, and Jennifer A. Horney. "The Impacts of Exposure to Environmental Risk on Physical and Mental Health in a Small Geographic Community in Houston, TX." Journal of Community Health 42 (2017): 813-818.

${ }^{39}$ City of Houston Department of Health and Human Services.Community health profiles: Harrisburg/Manchester super neighborhood, 1999-2003. 2004. <https://www.houstontx.gov/ health/chs/Harrisburg-Manchester.pdf>. (Last accessed on 16.03.15).
} 


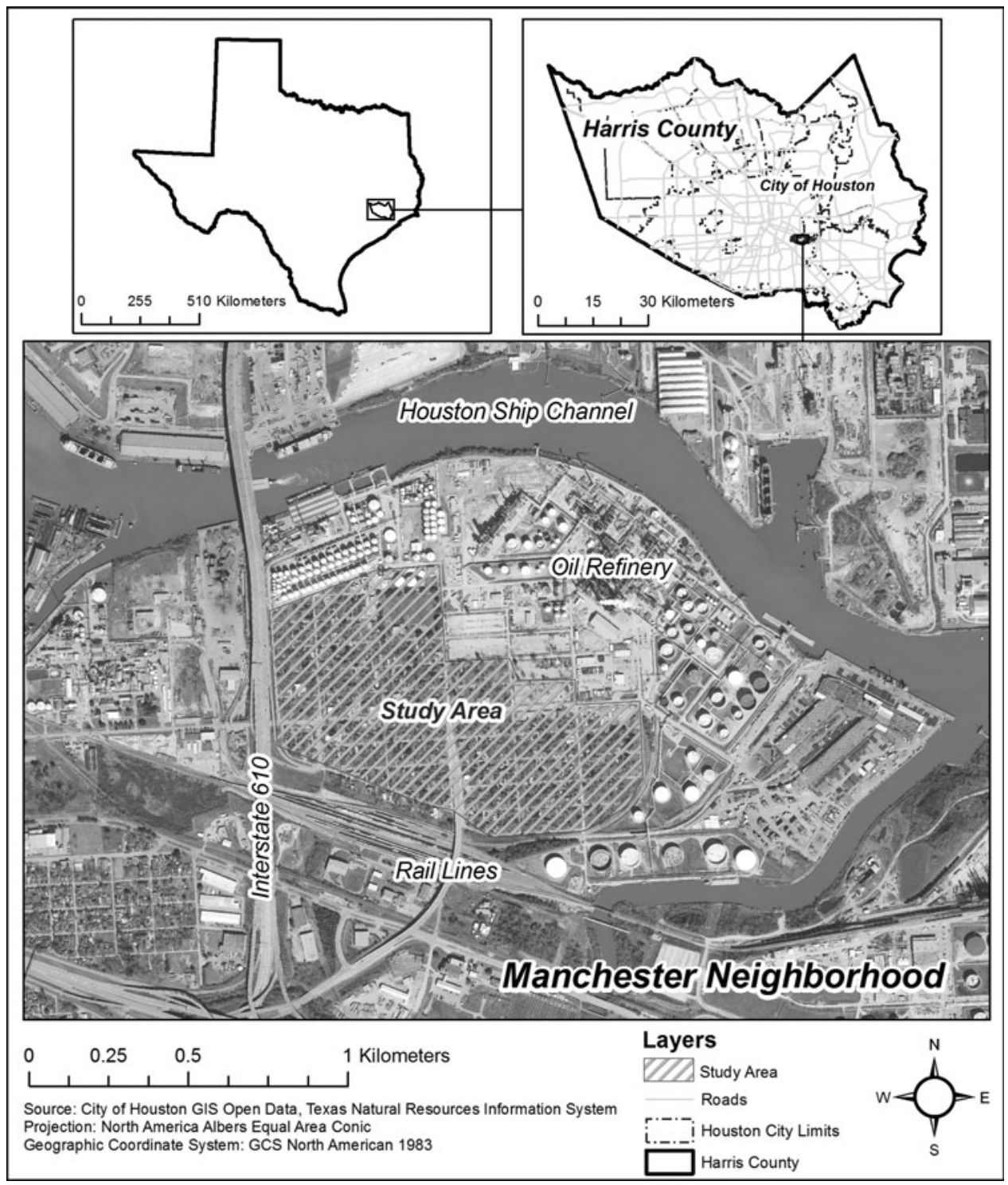

FIG. 1. Manchester Neighborhood, Houston, Texas.

resident contacted refused to participate, the next nearest home was approached by the team.

\section{Particulate wipes}

A particulate wipe was used to collect settled dust from noncarpeted flooring (tile, wood, or linoleum) located in the entryway of each home. Each team measured and marked a $1 \mathrm{~m}^{2}$ area and took one sample. After aseptically donning powder-free vinyl gloves, each team removed a prepared fiber filter cloth from a protective container. Approximately $5 \mathrm{~mL}$ of $100 \%$ isopropyl alcohol was applied to the cloth and the floor was cleaned starting at the top of the marked area and moving across and down in one continuous motion. The fiber cloth was then returned to the container, placed into a sterile polypropylene plastic resin bag, and placed into a cooler for transport. Upon arrival at the laboratory, samples were stored at $-4^{\circ} \mathrm{C}$ before extraction and analysis. These methods have been utilized and well described previously. ${ }^{40}$

\section{Sample analysis}

Each wipe was processed by pressurized fluid extraction in a Dionex ASE 200 Accelerated Solvent Extractor

\footnotetext{
${ }^{40}$ Christine Naspinski, Rebecca Lingenfelter, Leslie Cizmas, Ziad Naufal, Ling Yu He, Arif Islamzadeh, Zhiwen Li, Zhu Li, Thomas J. McDonald, and K.C. Donnelly. "A Comparison of Concentrations of Polycyclic Aromatic Compounds Detected in Dust Samples from Various Regions of the World." Environment International 34 (2008): 988-993; Stuart L. Shalat, Kirby C. Donnelly, Natalie C.G. Freeman, James A. Calvin, Sowmya Ramesh, Marta Jimenez, Kathleen Black, Catriona Coutinho, Larry L. Needham, Dana B. Barr, et al. "Nondietary Ingestion of Pesticides by Children in an Agricultural Community on the US/Mexico Border: Preliminary Results." Journal of Exposure Analysis and Environmental Epidemiology 13 (2003): 42-50.
} 
using a modified U.S. EPA Method 3545A. ${ }^{41}$ Extracts were analyzed for PAHs using a HP5890 gas chromatograph (HP5890; Hewlett Packard Company, Wilmington, DE) coupled with an Agilent 5972 mass spectrometer (GC-MS, Agilent 5972; Agilent Technologies, Santa Clara, CA). ${ }^{42}$ A HP-5MS capillary column (Agilent HP$5 \mathrm{MS} 60 \mathrm{~m}$ long with an interior diameter of $0.25 \mathrm{~mm}$ and $0.25 \mu \mathrm{m}$ film thickness, Agilent Technologies) was used to chromatographically separate the PAH analytes. Selected ion monitoring mode was used to identify and quantify PAH components. ${ }^{43}$ Data generated by GC-MS were quantified using the ChemStation program (ChemStation software, Agilent Technologies). The practical quantitation limit for each analyte was $0.01 \mu \mathrm{g}$ per milligram extract. These analyses have been previously well described by McDonald et al. ${ }^{44}$

\section{RESULTS}

Adult residents who consented to environmental sampling in their home using the wipes were also asked to complete a brief, interviewer-administered survey (Table 1). Twenty-five surveys and floor wipe samples were completed with an overall cooperation rate (number of completed interviews divided by eligible housing units that were contacted) of $61 \%$ (25/41). Of the respondents, 92\% self-identified as Hispanic $(n=23), 4 \%(n=1)$ as white non-Hispanic, and $4 \%(n=1)$ as other. Sixty-four percent $(n=16)$ of the respondents preferred the survey be completed in English with nine respondents completing it in Spanish. There were similar number of male $(n=12 ; 48 \%)$ and female $(n=13 ; 52 \%)$ respondents. The median age of respondents was 37 years and the median time living in the home was 17 years.

Surveys were used to account for potential sources of PAHs within the home. Only 1 of 25 households reported someone smoking a tobacco product within the home in the last 7 days. Forty-four percent of respondents $(n=11)$ used central air conditioning and $52 \%(n=13)$ used an air conditioning window unit. Twelve percent of respondents $(n=3)$ reported using an air purifier. The overall self-reported prevalence of chronic health conditions was high, with $72 \%(n=18)$ of respondents reporting having

\footnotetext{
${ }^{41}$ United States Environmental Protection Agency (USEPA). Hazardous waste test methods SW-846. 1998, <https://www .epa.gov/hw-sw846>.

${ }^{42}$ Thomas J. McDonald, Bo Wang, Susanne J. McDonald, and James M. Brooks. Quantitative determination of aromatic hydrocarbons using selected ion monitoring gas chromatography/ mass spectrometry. 2000. <https://www.tdi-bi.com/analytical services/environmental/NOAA_methods/Instrument $\% 20 \mathrm{PAH}$ .pdf>. (Last accessed on March 15, 2016).

${ }^{43}$ Jeffrey W. Short, Thomas J. Jackson, Marie L. Larsen, and Terry L. Wade. "Analytical Methods Used for Analysis of Hydrocarbons in Crude Oil, Tissues, Sediments and Seawater Collected for the Natural Resources Damage Assessment of the Exxon Valdez oil Spill." In: Stanley D. Rice, Robert B. Spies, Douglas A. Wolfe, and Bruce A. Wright (eds.), "Proceedings of the Exxon Valdez Oil Spill." American Fisheries Society Symposium 18 (1996): 140-148.

${ }^{44}$ McDonald et al. 2000.
}

Table 1. Respondent Household

Characteristics, Manchester Neighborhood, Houston, Texas $(N=25)$

\begin{tabular}{lr}
\hline & $\mathrm{n}(\%)$ \\
\hline Preferred language & \\
English & $16(64)$ \\
$\quad$ Spanish & $9(36)$ \\
Race/ethnicity & \\
$\quad$ Hispanic & $23(92)$ \\
$\quad$ White, non-Hispanic & $1(4)$ \\
Other & $1(4)$ \\
Employment status & \\
Employed $\geq 35$ hours per week & $14(56)$ \\
Employed <35 hours per week & $11(44)$ \\
$\quad$ or unemployed & \\
Source of drinking water & \\
$\quad$ Municipal water & $4(16)$ \\
Bottled water & $21(84)$ \\
Source of air conditioning & \\
$\quad$ Central air & $11(44)$ \\
$\quad$ Window unit & $13(52)$ \\
\hline
\end{tabular}

been told by their healthcare provider that a member of the household had asthma $(16 \% ; n=4)$, chronic obstructive pulmonary disease $(8 \%, n=2)$, any type of cancer $(16 \% ; n=4)$, kidney disease $(8 \%, n=2)$, dermatitis $(16 \%, n=4)$, or attention deficit disorder/attention deficit hyperactivity disorder $(8 \%, n=2)$.

\section{PAH surface loading}

Nineteen of the $61 \mathrm{PAH}$ analytes, including the EPA's 16 priority PAHs and the subgroup of 7 probable human carcinogens, were found in the sampled homes (Table 2). Eleven of 19 PAH analytes were present in $100 \%(n=25)$ of the homes sampled. There was a fairly consistent total PAH load in all homes (mean: $2.268 \mu \mathrm{g} / \mathrm{m}^{2}$; median: $1.619 \mu \mathrm{g} / \mathrm{m}^{2}$, with the exception of two outliers with a much higher total mass of PAHs present in the sample (range: 0.923 to $11.049 \mu \mathrm{g} / \mathrm{m}^{2}$ ) (Table 3). Based on the survey data, there are no obvious reasons for the higher readings of the two samples (e.g., smoking in home and exposure from place of employment). Although none of the sampled homes exceeded the EPA's Provisional Toxicity Values for Complex Mixtures risk-based screening levels, ${ }^{45}$ there are no derived toxicity values for inhalation exposures from most of the priority PAHs. This makes it difficult to determine whether or not these results should cause health concerns for the residents of the Manchester neighborhood. However, the daily screening level for naphthalene, which is available and is $700 \mathrm{ng} / \mathrm{m}^{3}$, is more than the highest level recorded in Manchester of $103 \mathrm{ng} / \mathrm{m}^{2}$.

\footnotetext{
${ }^{45}$ Environmental Protection Agency (EPA). Provisional PeerReviewed Toxicity Values for Complex Mixtures of Aliphatic and Aromatic Hydrocarbons (EPA/690/R-09/012F). (US EPA, Washington, 2009).
} 
Table 2. Polycyclic Aromatic Hydrocarbon AnAlytes Found Within Households, Manchester NeIghborhood, Houston, Texas $(N=25)$

\begin{tabular}{|c|c|}
\hline$P A H$ & No. of homes, $\mathrm{n}(\%)$ \\
\hline 2-Methylnaphthalene & $25(100)$ \\
\hline 2-Methylphenanthrene & $25(100)$ \\
\hline Acenaphthene $^{\mathrm{a}}$ & $23(92)$ \\
\hline Acenaphthylene $^{\mathrm{a}}$ & $25(100)$ \\
\hline Anthracene ${ }^{\mathrm{a}}$ & $25(100)$ \\
\hline Benz(a)anthracene $e^{a, b}$ & $25(100)$ \\
\hline Benzo(a)pyrene ${ }^{a, b}$ & $18(72)$ \\
\hline Benzo(b)fluoranthene $e^{a, b}$ & $20(80)$ \\
\hline $\operatorname{Benzo}(g, h, i) p^{2} r y l e n e^{a}$ & $22(88)$ \\
\hline $\operatorname{Benzo}(k, j)$ fluoranthene $e^{a, b}$ & $20(80)$ \\
\hline Chrysene $^{\mathrm{a}, \mathrm{b}}$ & $25(100)$ \\
\hline $\operatorname{Dibenzo}_{(\mathrm{a}, \mathrm{h}) \text { anthracene }} \mathrm{a}^{\mathrm{a}, \mathrm{b}}$ & $15(60)$ \\
\hline Fluoranthene $^{\mathrm{a}}$ & $25(100)$ \\
\hline Fluorene $^{\mathrm{a}}$ & $25(100)$ \\
\hline Indeno $(1,2,3-c, d)$ pyrene $e^{a, b}$ & $18(72)$ \\
\hline Naphthalene $\mathrm{a}^{\mathrm{a}}$ & $25(100)$ \\
\hline Phenanthrene $^{a}$ & $25(100)$ \\
\hline Pyrene $^{\mathrm{a}}$ & $25(100)$ \\
\hline Retene & $2(8)$ \\
\hline
\end{tabular}

${ }^{a}$ Analytes classified as priority pollutants by U.S. EPA (ATSDR, 2005).

${ }^{\mathrm{b}}$ Classified by U.S. EPA as probable human (B2) carcinogens (NTP, 2005).

EPA, Environmental Protection Administration; PAH, polycyclic aromatic hydrocarbon.

\section{Associations between PAH surface loading and demographic/household characteristics}

Odds ratios and 95\% confidence intervals were calculated using EpiInfo 7.0 (Atlanta, GA) to determine whether there were associations between demographic and household characteristics and PAH mass present in homes, as measured by quartiles (Table 4). Female respondents and household where a member was currently enrolled in school were about half as likely to be in the top quartile of PAH measurement. Those who used window units versus central air, those whose preferred language was Spanish versus English, and those who lived in their home $\geq 17$ years were 3.5-4.9 times as likely to have PAH loads in the top quartile. Owing to the small sample size, confidence intervals for all associations were imprecise and included the null value of 1.0.

\section{Potential sources of $P A H s$}

To assess the potential sources of PAHs, we calculated the ratios of specific PAHs (anthracene/anthracene plus phenanthrene $[\mathrm{A} / \mathrm{A}+\mathrm{P}]$ and fluoranthene/fluoranthene plus pyrene $[\mathrm{F} / \mathrm{F}+\mathrm{Py}])$ found in the wipes. These types of diagnostic ratios can be used to indicate either combus-

\footnotetext{
${ }^{46}$ Mark B. Yunker, Robie W. Macdonald, Roxanne Vingarzan, Reginald H. Mitchell, Darcy Goyette, and Stephanie Sylvestre. "PAHs in the Fraser River Basin: A Critical Appraisal of PAH Ratios as Indicators of PAH Source and Composition." Organic Geochemistry 33 (2002): 489-515.
}

Table 3. Total Polycyclic Aromatic Hydrocarbons (NG/M ${ }^{2}$ ) By Location, Manchester Neighborhood, Houston, Texas $(N=25)$

\begin{tabular}{lc}
\hline Sample no. & Total $P A H\left(\mu \mathrm{g} / \mathrm{m}^{2}\right)$ \\
\hline 1 & 2.119 \\
2 & 11.049 \\
3 & 1.180 \\
4 & 2.307 \\
5 & 8.503 \\
6 & 1.837 \\
7 & 1.650 \\
8 & 1.460 \\
9 & 1.640 \\
10 & 1.551 \\
11 & 1.692 \\
12 & 1.014 \\
13 & 1.800 \\
14 & 1.431 \\
15 & 1.619 \\
16 & 1.348 \\
17 & 2.216 \\
18 & 1.536 \\
19 & 0.923 \\
20 & 1.615 \\
21 & 1.441 \\
22 & 2.030 \\
23 & 1.447 \\
24 & 1.743 \\
25 & 1.551 \\
\hline
\end{tabular}

tion or other origins for the $\mathrm{PAHs} .{ }^{46} \mathrm{~A} / \mathrm{A}+\mathrm{P}$ ratio values $>0.10$ and $\mathrm{F} / \mathrm{F}+\mathrm{Py}$ ratios $>0.40$ indicate combustion as the dominant source. The ratios calculated from the filter wipes indicate combustion as the dominant source for the PAHs in Manchester (Table 5). Transportation infrastructure is a major potential exposure for residents, since the neighborhood of Manchester is bordered by the elevated 8-lane Interstate 610 Ship Channel Bridge, a 26lane Union Pacific railyard, and large industrial complexes with heavy truck traffic.

\section{DISCUSSION}

With the exception of two outliers with a very high mass of PAH present in the sample, there was a fairly consistent total PAH load in all homes. Based on the data collected as part of the survey, there are no obvious reasons for the higher readings from two samples (e.g., smoking in home and exposure from place of employment). Previous studies that have sought to quantify PAH loading in households have reported similar outliers. For example, Naspinski et al. ${ }^{47}$ evaluated PAH concentrations in settled household dust collected from 21 homes located in a rural Texas community, finding a range of total PAH loadings from 0.24 to $35.30 \mu \mathrm{g} / \mathrm{m}^{2}$. Differences between households can be attributed to a number of factors, including urban land use density and pavement

\footnotetext{
${ }^{47}$ Naspinski et al., 2008.
} 
Table 4. Associations Between Household AND DEMOGRAPHIC CHARACTERISTICS AND PolycyClic Aromatic Hydrocarbon QuARTILE, OdDS RATIO, AND 95\% CONFIDENCE INTERVALS

\begin{tabular}{ll}
\hline OR $(95 \% C I)$ & $\mathrm{p}$ \\
\hline
\end{tabular}

Respondent gender

Male

Female

$0.48(0.03-5.5)$

Employment status $<35$ hours per week $\geq 35$ hours per week $1.23(0.11-17.6)$

Household member enrolled in school No Yes $0.64(0.06-9.8)$

Years living in present home $<17$

$\geq 17$

$4.89(0.46-51.9)$

Years living in neighborhood $<17$ $\geq 17$ $1.50(0.20-11.0)$

Air conditioning

Central air Window units $4.00(0.30-216.3)$

Preferred language English Spanish $3.50(0.30-49.6)$

CI, confidence intervals; OR, odds ratio.

surface type ${ }^{48}$ outdoor PAH concentrations, home heating type, and age of the residence. ${ }^{49}$ Human activities such as removing shoes before entering the home, ${ }^{50}$ the use of incense and candles, ${ }^{51}$ household cleaning, ${ }^{52}$ and food preparation $^{53}$ may also affect residential PAH levels.

Current toxicological knowledge regarding inhalation exposure toxicity values and risks of PAH exposure in domestic settings is limited. Although the PAH levels recorded in Manchester homes do not exceed the EPAs toxicity values for complex mixtures, the levels are more similar to samples collected from homes with documented risk factors such as smoking or proximity to an industrial

${ }^{48}$ Barbara J. Mahler, Peter C. Van Metre, Jennifer T. Wilson, MaryLynn Musgrove, Teresa L. Burbank, Thomas E. Ennis, and Thomas J. Bashara. "Coal-tar-based Parking Lot Seal Coat: An Unrecognized Source of PAH to Settled Household Dust." Environmental Science \& Technology 44 (2010): 894-900.

${ }^{49}$ Todd Whitehead, Catherine Metayer, Robert B. Gunier, Mary H. Ward, Marcia G. Nishioka, Patricia Buffler, and Stephen M. Rappaport. "Determinants of Polycyclic Aromatic Hydrocarbon Levels in House Dust." Journal of Exposure Science \& Environmental Epidemiology 21 (2011): 123-132.

${ }^{50}$ Mahler et al., 2010.

${ }^{51}$ Mahler et al., 2010.

${ }_{53}^{52}$ Naspinski et al., 2008.

${ }^{53}$ Jane C. Chuang, Gregory A. Mack, Michael R. Kuhlman, and Nancy K. Wilson. "Polycyclic Aromatic Hydrocarbons and Their Derivatives in Indoor and Outdoor Air in an Eight-Home Study." Atmospheric Environment 25 (1991): 369-380. complex in other studies. For example, Hoh et al. ${ }^{54}$ evaluated PAH loading in settled household dust samples collected from smoking $(n=88)$ and nonsmoking $(n=42)$ residences in Southern California. Although only one resident in our study reported smoking inside the home in the prior 7 days, the median load of total PAHs observed in Manchester $\left(1.619 \mu \mathrm{g} / \mathrm{m}^{2}\right)$ was more similar to smoking homes $\left(1.650 \mu \mathrm{g} / \mathrm{m}^{2}\right)$ than nonsmoking homes $(0.796 \mu \mathrm{g} /$ $\mathrm{m}^{2}$ ). In another study, the total PAHs observed in Manchester were more analogous to settled house dust collected in a residential area close to an industrial complex in Sumgayit, Azerbaijan $\left(2.9 \mu \mathrm{g} / \mathrm{m}^{2}\right)$, than in a rural, agricultural community in Texas $\left(0.11 \mu \mathrm{g} / \mathrm{m}^{2}\right)$; however, Manchester PAHs were far lower than samples collected in a coal mining city in Shanxi Province, China $(162.0 \mu \mathrm{g} /$ $\left.\mathrm{m}^{2}\right) .{ }^{55}$ This presents some evidence that the health effects of PAH exposure should still be of concern to residents, even if they do not exceed the limited number of established risk levels. In addition, risk levels for both inhalational and oral exposure to the 16 EPA priority PAHs are urgently needed to improve our understanding of the health risks associated with chronic exposure.

Since diagnostic ratios consistently indicated combustion sources for the PAHs collected in Manchester homes, the location of transportation infrastructure should also be considered as a potential source of PAHs. Studies of PAHs in household dust in Germany have attributed PAHs in nonsmokers' homes to vehicular emissions. ${ }^{56}$ However, although the source of the PAHs is likely combustion, this does not indicate that homes are directly polluted as a result of proximity to transportation infrastructure. Although diagnostic ratios indicate the source of the domestic PAHs was combustion, we do not know how they entered the homes. For example, they could be brought into the home on people's shoes. Collection and analysis of outdoor pollution near the home could allow for the correlation of indoor and outdoor PAH levels. ${ }^{57}$

The effective translation of this type of research to residents, stakeholder groups, and policy makers is an essential next step to preventing future negative health impacts from domestic exposures to PAHs. The research team plans several avenues for research translation and outreach, including meetings with community nonprofits and in-person visits with each household who participated to share results and provide an explanation of the potential

\footnotetext{
${ }^{54}$ Eunha Hoh, Richard N. Hunt, Penelope J. E. Quintana, Joy M. Zakarian, Dale A. Chatfield, Beth C. Wittry, Edgar Rodriguez, and Georg E. Matt. "Environmental Tobacco Smoke as a Source of Polycyclic Aromatic Hydrocarbons in Settled Household Dust." Environmental Science \& Technology 46 (2012): 4174-4183.

${ }_{55}^{55}$ Naspinski et al., 2008.

${ }^{56}$ Hermann Fromme, Thomas Lahrz, Markus Piloty, $H$. Gebhardt, Arno Oddoy, and Henning Ruden. "Polycyclic Aromatic Hydrocarbons Inside and Outside of Apartments in an Urban Area." Science of the Total Environment 326 (2004): $143-439$.

${ }^{57}$ Maria Rosaria Mannino, and Santino Orecchio. "Polycyclic Aromatic Hydrocarbons in Indoor Dust Matter of Palermo (Italy) Area: Extraction, GC-MS Analysis, Distribution, and Sources." Atmospheric Environment 42 (2008): 1801-1817.
} 
Table 5. Polycyclic Aromatic Hydrocarbon Ratios, Anthracene/Anthracene Plus Phenanthrene and Fluoranthene/Fluoranthene Plus Pyrene $\left(\mu \mathrm{G} / \mathrm{M}^{2}\right)$, Manchester Neighborhood, Houston, Texas $(N=25)$

\begin{tabular}{rcccccc}
\hline Sample & Anthracene & Phenanthrene & $A / A+P$ & Fluoranthene & Pyrene & $F / F+P$ \\
\hline 1 & 0.037 & 0.235 & 0.136 & 0.091 & 0.063 & 0.589 \\
2 & 0.086 & 0.288 & 0.229 & 0.276 & 0.231 & 0.544 \\
3 & 0.017 & 0.086 & 0.165 & 0.039 & 0.044 & 0.473 \\
4 & 0.039 & 0.128 & 0.235 & 0.139 & 0.103 & 0.574 \\
5 & 0.140 & 0.325 & 0.301 & 0.750 & 0.541 & 0.581 \\
6 & 0.029 & 0.130 & 0.181 & 0.041 & 0.0358 & 0.535 \\
7 & 0.038 & 0.112 & 0.252 & 0.064 & 0.051 & 0.554 \\
8 & 0.023 & 0.087 & 0.211 & 0.023 & 0.020 & 0.533 \\
9 & 0.028 & 0.144 & 0.163 & 0.093 & 0.074 & 0.558 \\
10 & 0.020 & 0.098 & 0.170 & 0.038 & 0.034 & 0.527 \\
11 & 0.019 & 0.081 & 0.192 & 0.017 & 0.017 & 0.494 \\
12 & 0.044 & 0.070 & 0.386 & 0.066 & 0.055 & 0.547 \\
13 & 0.023 & 0.087 & 0.211 & 0.026 & 0.024 & 0.523 \\
14 & 0.029 & 0.166 & 0.150 & 0.103 & 0.063 & 0.620 \\
15 & 0.020 & 0.075 & 0.213 & 0.043 & 0.037 & 0.539 \\
16 & 0.024 & 0.094 & 0.201 & 0.070 & 0.073 & 0.489 \\
17 & 0.020 & 0.068 & 0.224 & 0.017 & 0.016 & 0.510 \\
18 & 0.018 & 0.065 & 0.212 & 0.022 & 0.013 & 0.622 \\
19 & 0.018 & 0.092 & 0.162 & 0.071 & 0.054 & 0.566 \\
20 & 0.0228 & 0.102 & 0.179 & 0.064 & 0.057 & 0.531 \\
21 & 0.024 & 0.104 & 0.187 & 0.070 & 0.067 & 0.514 \\
22 & 0.021 & 0.073 & 0.220 & 0.053 & 0.045 & 0.540 \\
23 & 0.037 & 0.134 & 0.216 & 0.043 & 0.037 & 0.540 \\
24 & 0.025 & 0.111 & 0.184 & 0.053 & 0.038 & 0.581 \\
25 & 0.0201 & 0.098 & 0.170 & 0.038 & 0.034 & 0.527 \\
\hline
\end{tabular}

$\mathrm{A} / \mathrm{A}+\mathrm{P}$, anthracene/anthracene plus phenanthrene; $\mathrm{F} / \mathrm{F}+\mathrm{P}$, fluoranthene/fluoranthene plus pyrene.

health consequences of exposure and to present potential interventions. Meetings with policy- and decision makers are also planned to present potential interventions. Further data collection, including soil, surface water, and biological samples, is also planned.

This study has several important limitations. The size of the sample was small. However, Manchester is a very compact neighborhood in East Houston with fewer than 300 occupied housing units, so this small sample did include $\sim 10 \%$ of the occupied homes in the neighborhood. The method used for collection of the samples, while requiring minimal equipment and training, does not allow for measurement of contaminant concentration based on either the mass of contaminant per mass of dust or the mass of contaminant in a specific particle size of dust. The calculation of these types of concentrations is not possible since we did not assess the total weight of the sample, allowing for the calculation of a concentration of PAH by total mass, but instead collected total PAH loading by area. Although previous research suggests that the measurement of PAH concentrations by area may be more suitable than quantification by mass in settled household dust since they can provide information related to potential sources of contaminants, ${ }^{58}$ these data cannot be used directly in an exposure calculation. ${ }^{59}$

\section{CONCLUSION}

This small pilot study is an important first step in attempting to quantify chronic exposure to toxic pollution from industry, including oil refineries, chemical plants, a metal recycling facility, and from major transportation infrastructure, including the Interstate 610 Ship Channel Bridge and a 26-lane industrial rail yard, in neighborhoods locations near the Houston Ship Channel. More prospective research is needed to identify potential causal pathways and to translate research findings into effective risk reduction strategies.

\section{AUTHOR DISCLOSURE STATEMENT}

No competing financial interests exist.

Address correspondence to: Jennifer A. Horney

Department of Epidemiology and Biostatistics Texas A\&M School of Public Health 1266 TAMU

College Station, TX 77843

E-mail: horney@sph.tamhsc.edu

\footnotetext{
${ }^{58}$ Hoh et al., 2012.

${ }^{59}$ Naspinski et al., 2008.
} 